\section{Book reviews}

Concise Renal Pathology. FE Dische. (Pp 214; £48.) Castle House Publications. 1987. ISBN 0-7194-0115-1.

This book is indeed what its title depictsnamely, a straight forward account of the various disease processes which affect the kidney, and indeed the range of disorders included is remarkably comprehensive. I felt, however, that there were a few areas of over simplification which were misleading. Thus the relationship between mesangial and focal proliferative glomerulonephritis was not explained and the relevance of the development of crescents in relation to glomerular diseases could have benefitted from a more detailed analysis. Perhaps these points reflect a personal bias and do not detract from the overall impression of an uncomplicated view of renal pathology.

The first chapter deals with clinical presentation and was written by Victor Parsons. It is a useful introduction but does not lead easily into the rest of the book which I think is a pity because clinical presentation is clearly an important part of diagnosis.

The illustrations are clear and the book is pleasantly set out. The author has included many electron micrographs which he felt would be of value in explaining the complexities of glomerular disease. Whilst this is true of some of the illustrations, others I think are quite complex, and a person approaching renal pathology for the first time may have difficulty in understanding precisely what is being referred to in the legend. There were a few minor errors which were misleading such as the fact that figures 7.5 and 7.6 seemed to be reversed with regard to their legends and the legend for 13.13 did not seem to make sense. Sadly the typesetter managed to misspell Robert Heptinstall's name which occurs in emboldened type in the Preface.

Overall this is a straightforward comprehensive account of renal disease with good illustrations which is very easy to read. From my personal view, I would have preferred to see more diagrams and to read a more colourful text, but nevertheless, I think many readers who are daunted by the more complex texts on renal pathology will find this a most valuable book. It is certainly a gentle introduction. I wish it well.

DR TURNER
Notices

United States and Canadian Academy of Pathology

The Annual Meeting of the United States and Canadian Academy of Pathology will be held at the Washington Hilton in Washington, DC, from Sunday February 28 to Friday March 4, 1988.

Scientific papers, poster sessions, 13 specialty conferences, and 49 short courses are scheduled. Two special courses will be offered on immunopathological techniques in diagnostic pathology with Drs Robert McCluskey and Robert Colvin as course directors; and electron microscopy in surgical pathology with Dr Bruce MacKay as course director. The long course will be on gastrointestinal pathology with Drs Harvey Goldman and Henry Appelman as course directors.

Timely topics in pathology will feature a session on technology transfer-the new molecular pathology, opportunities for the future presented by Dr Cecilia Fenoglio-Preiser.

Further information about the meeting and courses may be obtained from $\mathrm{Dr}$ Nathan Kaufman, Secretary-Treasurer, United States and Canadian Academy of Pathology, Inc, Building C, Suite B, 3515 Wheeler Road, Augusta, Georgia 30909.

\section{European Association for} Haematopathology

Announcing the formation of the Euro pean Association for Haematopathology:

This association has been formed $\frac{0}{8}$ further the study of diseases of the haematopoietic and lymphoreticulas. systems and to promote the exchange and dissemination of knowledge corn cerning their diagnosis and treatment.

Qualified pathologists who have shown an active interest in haes matopathology will be eligible for futt membership. Associate membership wiff be available to medical doctors and basis scientists with an interest in haes matopathology and residents, fellow and trainees in haematopathology.

The first meeting will take place in Geneva from 11-15 April 1988. The programme for this meeting will be: 11-12 April tutorial for trainees in hae matopathology

12-14 April seminars on Hodgkin's and non-Hodgkin's lymphomas and extray nodal lymphomas

14-15 April workshop

If you wish to apply for membership of the European Association for matopathology, or to attend the Gexieva meeting, please write to: Professor Eact Lennert, Institute for Pathology, chaelisstrasse 11, D-2300 Kiel, W Gep many.

\title{
Benjamin Castleman Award
}

The Benjamin Castleman Award is granted for an outstanding paper in the field of human pathology published in English. The 1988 award will be based on papers published during the calendar year 1987. The subject may represent any topic in pathology but must be based on human material with emphasis on morphological or anatomical approaches. For papers with multiple authorship only one author is $\varrho$ eligible. The awardee must be a qualified or trainee pathologist who has not yet reached his or her 40th birthday in 1987. Papers by pathology residents, trainees, 음 and fellows are encouraged. The prize will consist of a check for $\$ 1000$ and a certificate.

Nominations should consist of 12 reprints or preprints of the manuscript and a letter attesting to the nominee's age, dates, and places of residency training, and role $\mathrm{N}$ in the investigation if other than the first author.

This award, financed by contributions to a fund established by former students 0 and trainees of Dr Castleman, will be presented at the annual meeting of the United $\mathrm{\omega}$ States and Canadian Academy of Pathology in 1988 (in Washington, DC, February 28-March 4).

Nominations (by January 15 1988) should be submitted to: United States and $\stackrel{0}{\leftarrow}$ Canadian Academy of Pathology Building C, Suite B, 3515 Wheeler Road, Augusta, GA 30909. 